\title{
O caso das creches e o Poder Judiciário: uma questão de justiças
}

Maike Wile dos Santos e Yan Villela Vieira

\section{Resumo}

Este artigo pretende tratar, de forma simplificada e sintetizada, da distinção entre justiça distributiva e justiça comutativa no raciocínio jurídico. Também pretende apontar alguns dos problemas que a aplicação equivocada desses conceitos pode causar. Para isso, foi utilizado um caso judicial paradigmático, que permite a análise de como o Poder Judiciário lidou com uma questão envolvendo um bem comum. O tema julgado se insere na área dos direitos fundamentais, enquanto esse artigo pretende uma aplicação da teoria geral do direito e filosofia moral, relacionando estas duas disciplinas.

Palavras-chave: Direitos Fundamentais - Justiça Comutativa - Justiça Distributiva - Poder Judiciário - Creches. 


\section{Introdução e justificativa}

Este artigo pretende tratar normativamente de duas questões e suas interligações no raciocínio jurídico mediante análise de uma decisão judicial. A primeira é a distinção entre justiça comutativa e justiça distributiva e a relevância dessa distinção, que será retomada de maneira breve a partir da tradição clássica. A segunda é a falsa solução jurídica a que a confusão entre esses dois conceitos pode conduzir e tem conduzido. O caso escolhido é um hard case ${ }^{\mathrm{I}}$ referente à falta de vagas em creches no estado de São Paulo². Primeiramente, fazemos algumas proposições teóricas fortes.

Toda regra tem uma espécie de "penumbra", sendo seu significado incerto, o que é uma característica da imprecisão da linguagem ${ }^{3}$. Nesse sentido, as práticas jurídicas estão mais próximas das práticas linguísticas que daquelas práticas características das ciências naturais. Isso, no entanto, não significa que não haja decisões jurídicas melhores ou piores. A diferença é que essa constatação se dá de maneira diversa, mediante argumentação, e não mediante evidências empíricas. Direito não é simples questão de opinião, mas também não pode ser provado no interior de um laboratório.

Partimos da premissa de que a boa prática jurídica é a que se dá com clareza conceitual na argumentação. Antes de explorar a retórica, é necessário ter clareza na tópica ${ }^{4}$. Dessa forma, acreditamos que a distinção entre justiça comutativa e justiça distributiva ajuda a raciocinar de maneira mais clara no disputado terreno do direito.

Saber manejar esses conceitos na prática é fundamental para uma boa decisão judicial. Tratando-se de questões que envolvem um bem comum (como

I "Um caso difícil é uma situação no direito que dá origem a discussão genuína a respeito da verdade de uma proposição de direito que não pode ser solucionada por recurso a um conjunto de fatos evidentes determinantes da questão." Esta definição está no livro de GUEST, 20IO, p. I63.

2 Este problema foi bastante divulgado na mídia: Falta de vagas em creches de SP atinge 175 mil crianças (http:// gI.globo.com/sao-paulo/noticia/2OI2/O2/falta-de-vagas-em-creches-de-sp-atinge-I75-mil-criancas. html), Com fila de 127 mil crianças em SP, pais vão à Justiça pedir vaga em creche (http://educacao.uol.com.br/noticias/20I3/o8/29/com-fila-de-I27-mil-criancas-em-sp-pais-vao-a-justica-pedir-vaga-em-creche. $\mathrm{htm}$ ), Estudo aponta falta de 150 mil vagas em creches de São Paulo (http://noticias.terra.com.br/educacao/estudo-aponta-falta-de-I50-mil-vagas-em-creches-de-sao-paulo, 8455fb56c76904IoVgnGLD2000000dc 6eboaRGRD.html), entre outros. Acesso em: 31/05/20I4.

3 H. L. A. HART chama essa condição de "textura aberta", e aborda esta característica no livro $O$ conceito de direito, principalmente no capítulo "Os fundamentos de um sistema jurídico" (Cf. HART, 2OI2).

4 Para este trabalho, entendemos que a retórica diz respeito à solução das dúvidas sobre a premissa menor do raciocínio jurídico. A tópica diz respeito à solução das dúvidas sobre a premissa maior do raciocínio jurídico. 
o caso selecionado), tal diferenciação é ainda mais pertinente, pois tanto a justiça distributiva quanto a justiça comutativa seguem uma lógica própria. Aplicar uma lógica inadequada ao caso significa decidir de maneira injusta. E se a justiça é o que dá sentido ao direito, decidir de maneira injusta significa subverter o próprio direito.

Como dito anteriormente, as afirmações acima possuem elevada carga conceitual e demandam uma justificação. A próxima seção tem esse objetivo, procurando fundamentar e aprofundar o que foi argumentado, para posteriormente passar à crítica da decisão do caso. É preciso que fique claro, portanto, que o desacordo quanto ao que for apresentado a seguir altera a validade da análise como um todo. Por fim, destacamos que a construção argumentativa abaixo apenas se utiliza de uma tradição teórica existente, sem propor uma teoria geral a partir do nada. Nosso objetivo, afinal, não é a busca de uma teoria do direito, mas a apresentação do que parece ser uma teoria aceitável, e a demonstração de que determinadas formas de raciocínio jurídico não se coadunam a ela.

\section{O caso e seu raciocínio ${ }^{5}$}

Lucas do Carmo Brandão, menor representado por sua mãe, Lucimeire Santos do Carmo, impetrou mandado de segurança ${ }^{6}$ contra ato da Secretaria Municipal da Educação do município de Paulínia, pois, apesar de inscrito em uma vaga em creche pública municipal, a vaga não lhe foi concedida. A sentença inicial entendeu procedente o pedido, nos termos dos artigos 205 e 208, IV, da Constituição Federal ${ }^{7}$, determinando que a autoridade coatora fornecesse a vaga em creche ao menor, no prazo de cinco dias.

O município apelou, sustentando ausência de direito líquido e certo em favor do impetrante. Argumentou, em síntese, que se estaria pretendendo transferir ao Estado uma obrigação que é da própria família, uma vez que a

5 TJ: MS oI31292-70.2007.8.26.000/SP, rel. min. Osni de Souza, j. 28/06/20II.

6 Art. 5ำ, LXIX, da Constituição Federal: Conceder-se-á mandado de segurança para proteger direito líquido e certo, não amparado por "habeas-corpus" ou "habeas-data", quando o responsável pela ilegalidade ou abuso de poder for autoridade pública ou agente de pessoa jurídica no exercício de atribuições do Poder Público.

7 Art. 205, LXIX, da Constituição Federal. A educação, direito de todos e dever do Estado e da família, será promovida e incentivada com a colaboração da sociedade, visando ao pleno desenvolvimento da pessoa, seu preparo para o exercício da cidadania e sua qualificação para o trabalho. Art. 208. O dever do Estado com a educação será efetivado mediante a garantia de: IV - educação infantil, em creche e pré-escola, às crianças até 5 (cinco) anos de idade. 
única obrigação do Estado é a de garantir educação escolar pública, que não inclui a educação infantil. Haveria ainda limitação na disponibilidade de vagas. Por fim, argumentou que a sentença extrapolava a competência do Judiciário, interferindo nas políticas educacionais do município.

A 8 ${ }^{\text {a }}$ Câmara de Direito Público do Tribunal de Justiça de São Paulo negou provimento à apelação, argumentando que houve lesão a direito líquido e certo, mantendo a sentença recorrida. Sustentou essa posição mediante uma série de casos análogos envolvendo o município de Paulínia em que se concedeu vaga em creche àqueles que recorreram ao Judiciário, além dos dispositivos constitucionais citados em nota de rodapé.

A solução do caso pode causar algum incômodo intuitivo por tratar de um bem que, segundo a Constituição, é garantido a todas as pessoas, o que não ocorre na prática. No entanto, a decisão parece obedecer às regras do raciocínio jurídico. Vejamos sua estrutura simplificada:

a. Todas as pessoas de até 5 anos de idade têm direito a uma prestação do Estado na forma de creche gratuita;

b. Uma pessoa de até 5 anos de idade não está na "posse" dessa prestação, reclamando atividade judicial que a garanta;

c. A pessoa reclamante tem o direito a que a decisão judicial obrigue a transferência da prestação estatal para sua "posse".

Esse modelo corresponde imperfeitamente ao método de dedução por silogismo ${ }^{8}$. O item (a) corresponde à premissa maior, o item (b) à premissa menor e (c) à conclusão. Não questionamos aqui a utilidade do raciocínio silogístico para a prática do direito. No entanto, é importante desenvolver um pouco melhor os pressupostos do item (a):

a. Todas as pessoas de até 5 anos de idade têm direito a uma prestação do Estado na forma de creche gratuita;

i. O preenchimento de determinada condição (fato bruto, no caso, a idade) aciona um mecanismo institucional;

ii. O Estado tem o dever de responder ao acionamento deste mecanismo institucional com a disponibilização de uma vaga em creche pública;

iii. A relação entre o indivíduo que preenche a condição determinada e o Estado é obrigacional, deste em relação àquele.

8 Sobre o silogismo como método de aplicação do direito, ver ENGISGH, 2008. 
O desenvolvimento dessa seção precisa ser suspenso para a formulação das bases teóricas que seguiremos para a crítica do caso. Retomaremos o problema do raciocínio como deixado aqui em breve.

\section{Direito e sentido}

Apesar de não pretendermos discorrer aqui sobre todo o debate acerca da natureza e do sentido do direito, é necessário apontar quais referenciais teóricos adotaremos como fundamentos de nossa análise. $\mathrm{O}$ argumento básico desta seção é que o direito é uma realidade institucional cuja ação é constituída por um uso da razão prática ${ }^{9}$. Abaixo desenvolvemos rapidamente o que pretendemos dizer com "realidade institucional" e "uso da razão prática". Uma vez feito isso, construiremos a relação que há entre ambos quanto ao direito entendido como ação. Por fim, fazemos uma ressalva quanto ao raciocínio jurídico utilizado no caso, apontando diretamente qual sua primeira falha.

Realidades institucionais são uma forma de realidade social objetiva, ou seja, são criadas por pessoas sem depender de sua subjetividade. Essa ideia parece representar um absurdo, já que afirma a existência de algo sem correspondente físico, mas separado da imaginação de cada indivíduo. No entanto, é possível defendê-la tendo em vista a existência de certos elementos comuns ao que chamamos "instituições". São estes (a) intencionalidade coletiva, definida como uma vontade de realizar algo baseada em "nós", e não apenas em "eu"; (b) atribuição de funções, que torna possível se estabelecer uma normatividade sobre fatos; (c) regras constitutivas, que não regulam situações já existentes, e sim criam novas ${ }^{\mathrm{IO}}$.

A relevância desses elementos é de que, quando presentes simultaneamente, são capazes de criar funções de status. Isso significa que, a partir da subjetividade de um grupo, é possível que uma realidade separada, formada por funções de status interconectadas, crie e controle fatos brutos de existência física. O exemplo clássico é o do dinheiro (SEARLE, 2000), uma realidade institucional ligada a papéis ou dígitos em contas bancárias, sem correspondente físico, que reúne os elementos anteriores e é capaz de atribuir status a

9 Acompanhamos, quanto a essa caracterização, a teoria do direito de MacCORMICK, 2008, preâmbulo de I994, p. IX.

Io Todo o desenvolvimento dessa ideia de realidades institucionais se deve ao trabalho de SEARLE, 2000, p. I05-125. 
determinadas situações do mundo real. Com isso, a realidade do dinheiro é capaz de alterar a existência física do mundo, com a compra de mercadorias, por exemplo.

O segundo conceito que é necessário retomar de uma tradição filosófica é o de razão prática. Esta é uma categoria da razão utilizada para decidir como agir diante de uma situação determinada, o que a torna muito próxima do raciocínio moral. Seu funcionamento, ao contrário do sustentado por uma visão subjetivista ou relativista da moral ${ }^{\text {II }}$, tem semelhanças com a lógica. É formado basicamente pela possibilidade do indivíduo dar um "passo atrás" no momento de decidir, colocando-se em um ponto de vista universal para analisar se todos os que se encontram em sua mesma situação deveriam agir de determinada maneira ${ }^{12}$.

Definir esses conceitos, no entanto, não é nosso objetivo principal, e, sim, argumentar que ambos são necessários para a compreensão do direito como ação, o que possibilita afirmar que sua aplicação correta depende de considerações de justiça. É fácil aceitar que o direito é uma instituição, podendo ser compreendido de maneira objetiva dentro do modelo acima. Essa consideração deu forma às teorias positivistas mais simples, de caráter puramente epistemológico ${ }^{13}$. A maior dificuldade está na relação entre esse fato institucional e qualquer raciocínio de ordem moral, algo negado por essas teorias.

Esse problema é resolvido pela caracterização do direito como uma ação que interfere diretamente na liberdade de indivíduos e em sua vida moral. Trazemos assim dois novos argumentos que discutiremos separadamente.

Primeiramente, como ação o direito precisa ser orientado a um fim para adquirir sentido. Sua interpretação como simples conjunto de regras tornaria impossível compreender qual é o seu elemento de intencionalidade coletiva. Com isso, não haveria qualquer possibilidade de encontrar respostas corretas, ficando a prática da instituição do direito algo como um jogo sem sentido. Antecipando o que explicaremos abaixo, reconhecer que o direito tem um sentido e não o buscar seria fazer jogadas a esmo.

Em segundo lugar, ter em vista que o direito implica em invasões da liberdade e da moral individual aponta para a apreensão de sua finalidade como

II Isso provavelmente ficará claro no desenvolvimento do argumento, mas faço, desde logo, a ressalva de que não trato da moral positiva da sociedade, e, sim, de uma moral crítica.

12 A ideia do "passo atrás" como objetividade do raciocínio moral é desenvolvida em NAGEL, 200I, p. $128-\mathrm{I} 47$.

I3 O exemplo comum de autor que defendeu em sua obra uma visão desse tipo é o de KELSEN, 20 IO. 
algo dentro da moral, mais especificamente da justiça. $\mathrm{O}$ motivo disso é que uma justificativa moral é necessária para legitimar esse tipo de ação. Mais relevante ainda é o fato de que o próprio conceito de direito envolve uma espécie de moralidade interna no tratamento que as leis dão às pessoas, principalmente em seu aspecto de generalidade e conhecimento prévio por aqueles submetidos a sua coerção (MacGORMIGK, I985, p. I8-30).

Esses argumentos conduzem à conclusão de que o direito, para fazer sentido, precisa lidar com algumas questões típicas da argumentação moral. Con-

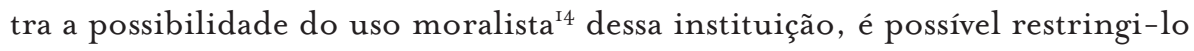
apenas a seu aspecto moral necessário. Esse é exatamente o escopo da justiça, seção da moralidade caracterizada por ser um dever-para-os-outros capaz de definir os sentidos de dano, reparação e distribuição de bens com os quais o direito costuma lidar (MacGORMICK, I985, p. 30-37).

Concluímos esta parte com uma ressalva que aponta a primeira e maior falha do raciocínio utilizado no caso. Assumimos que a aplicação de uma premissa maior, constituída do sentido das normas, a uma premissa menor, relativa aos fatos, é a base do raciocínio jurídico. No entanto, a formulação dessa premissa maior depende de se trabalhar corretamente uma tópica, ou seja, de uma apreensão do sentido do direito como formulado acima. Nesse ponto, o juízo falhou completamente. A ressalva que fazemos é que o problema aqui não é, como se costuma apontar, a ausência de uma ponderação de princí$\operatorname{pios}^{15}$. Não acreditamos que um recurso desse tipo poderia ajudar no caso; pelo contrário, poderia tornar o juízo feito no caso mais irracionalista ${ }^{\mathrm{I} 6}$. A falha foi a desatenção com o tipo de justiça que deveria ter orientado o juízo jurídico dessa situação, formando uma premissa maior equivocada por falta de profundidade.

\section{Uma questão de justiças}

A seção anterior tratou da formação equivocada de uma premissa maior pela desconsideração de que o direito é orientado pela justiça e que essa possui ao menos dois tipos. Esta seção diferencia as formas assumidas pela justiça,

I4 Este uso "moralista" seria aquele em que se pretende invadir todas as esferas da vida com as regras do direito. É o caso da pretensão de regrar a sexualidade com base em uma suposta moralidade sexual. I5 A ponderação de princípios contra a aplicação "formalista" de regras tem sua base no ataque de DWORKIN ao positivismo, trazido principalmente em DWORKIN, 20IO, p. 23-72.

I6 Uma crítica nesse sentido é feita por LIMA LOPES, 2003, p. 49-64. 
apontando qual a justiça utilizada na decisão e qual deveria ter sido considerada. Este erro constitui a segunda falha do caso, intimamente ligada à anterior.

A distinção clássica, que adotamos, se refere à separação entre justiça distributiva e comutativa. Aristóteles, em Ética a Nicômaco, distingue justiça distributiva (A) da justiça comutativa-retributiva (B) nos seguintes termos:

Da justiça particular e do que é justo no sentido correspondente: (A) uma espécie é a que se manifesta nas distribuições de honras, dinheiro ou outras coisas que são divididas entre aqueles que têm parte na constituição (pois aí é possível receber um quinhão igual ou desigual de outro); e (B) outra espécie é aquela que desempenha um papel corretivo nas transações entre indivíduos (ARISTÓTELES, 200I, p. 95).

A atenção com essa diferença entre tipos de justiça é fundamental para orientar a decisão de um conflito, pois altera a interpretação devida na construção da premissa maior. A consequência de não a levar em conta é a produção de decisões que aplicam a justiça comutativa, característica das relações entre indivíduos, a casos de justiça distributiva, em que um ou mais indivíduos se relacionam com um bem comum.

Essa é exatamente a segunda falha do acórdão. Ao não buscar o sentido da justiça envolvida, mesmo aplicando normas, foi feita uma jogada a esmo quanto ao "jogo" do direito. O raciocínio aplicado de encontrar uma norma que dê suporte à pretensão da parte e então lhe garantir isso usa uma lógica de justiça comutativa, como se o Estado fosse apenas um prestador de serviços para os indivíduos. O que deveria ter sido considerado antes da decisão é que as vagas em creches fazem parte de um bem comum, tanto no aspecto de como será feita a divisão entre as vagas existentes quanto no aspecto de como o orçamento do município será empregado para propiciar a educação infantil. Esse aspecto de uma relação entre indivíduos que compartilham um bem comum é típico da justiça distributiva, e não da comutativa.

Por isso, as duas falhas estão conectadas: o raciocínio jurídico insuficiente por não buscar o sentido das normas diante da justiça levou a um resultado que, conforme pode-se argumentar, violou a igualdade entre os cidadãos que partilham do mesmo bem comum.

Esse é apenas um entre os milhares de casos que chegam ao Judiciário envolvendo questões coletivas, como distribuição e realocação de recursos escassos. Um sistema jurídico incapaz de prover uma distribuição justa e justificável perde legitimidade perante os cidadãos. Esses novos conflitos trazem consigo uma série de paradigmas a serem superados, principalmente no que diz 
respeito à alocação ou apropriação individual de recursos comuns, levantando diversas questões sobre justiça e justificação das distribuições.

O paradigma novecentista de direito pressupunha que a simples existência de regras de justiça comutativa-retributiva levaria a uma sociedade em que se faria, automaticamente, justiça distributiva (LIMA LOPES, I994a, p. 28). A justiça distributiva, nesse cenário, tornou-se questão de política, e a justiça comutativa-retributiva tornou-se questão de direito. Essa distinção entre política e direito está hoje em crise; pautar o debate nesses termos, além de vulgar, é um anacronismo que pode levar a distorções institucionais, a decisões injustas e, dessa forma, à deslegitimação do sistema jurídico ${ }^{\mathrm{I7}}$.

Os temas que, hoje, têm chegado ao Judiciário são predominantemente de justiça distributiva. Uma política pública de fornecimento de vagas em creche não pode ser compreendida senão como uma disputa referente a um bem comum, que não é o interesse do Estado, nem da maioria, nem da minoria.

O bem comum diz respeito não só ao conjunto de condições que permite aos membros de uma comunidade atingir por si mesmos objetivos razoáveis, mas também ao processo pelo qual se desvalidam regras e normas, se questiona a justiça do status quo e se alteram as categorias sociais criadas normativamente (LIMA LOPES, I994a, p. 27). Ele é a base de nossa identidade enquanto cidadãos. Quando se discute justiça distributiva, é necessário deixar de lado concepções particulares de vida boa e adotar uma "concepção política de indivíduo" (RAWLS, I993, p. 29-3I), adotando um ponto de vista de lugar nenhum (ideia desenvolvida por NAGEL, I989). Assim, em se tratando de bens comuns, a lógica que se aplica é justamente a lógica da justiça distributiva.

\section{v. A falsa solução jurídica}

Dessa perspectiva, a sociedade não deveria ser entendida como uma simples soma de indivíduos, pois essa visão impossibilita a compreensão de conflitos distributivos. A justiça distributiva diz respeito à divisão ou apropriação individual do fundo social comum (LIMA LOPES, I994a, p. 26). O problema está justamente na determinação dos critérios em que isso se dá.

I7 Nesse sentido, Lima Lopes afirma: "em termos institucionais, dá-se a sobrecarga do órgão encarregado de resolver controvérsias, pela incapacidade de outros órgãos (Administração, Parlamento) de forjarem acordos universalizáveis ou simplesmente buscarem um interesse público ou comum. Trata-se de uma tensão permanente entre aplicação retrospectiva de leis tradicionais em situações novas, gerais e que precisam de regulação prospectiva” (LIMA LOPES, I994a, p. 25). 
No caso selecionado, houve aplicação de uma lógica comutativa-retributiva ao invés de uma lógica distributiva. A parte do orçamento destinada à política pública de creches constitui um bem comum. Nesse sentido, conceder a vaga da forma como se concedeu, argumentando-se como se argumentou, é subverter a justiça a ser aplicada e, assim, subverter a solução jurídica dada.

Entendeu-se que havia um direito individual (direito líquido e certo a uma vaga na creche municipal) decorrente de um direito coletivo (direito à educação). Entendeu-se que um direito coletivo é a soma de direitos individuais, quando na verdade os paradigmas de ambos são bastante diferentes.

Em parte, isso decorre do silêncio do Parlamento e da Administração pública em estabelecer critérios de distribuição - as vagas nas creches municipais serão destinadas a quem? Não questionamos, aqui, se os critérios são justos ou não, mas, sim, a falta de critérios. Diante do silêncio do Parlamento, como lidar com questões relativas à distribuição de um bem comum?

Num contrato, é fácil determinar o que é devido a quem. Entretanto, em se tratando de um bem comum, não se vê imediatamente o que é devido a quem, e em quais proporções. Decisões que, sob o pretexto de fazer justiça comutativa-retributiva - como o caso em questão - estão, de fato, tratando de justiça distributiva, geram tratamento desigual, subvertendo a própria aplicação.

\section{vi. Conclusão}

Acreditamos que o direito seja uma prática institucional, voltada à cooperação social, cujo sentido é dado pela ideia de justiça. Neste breve ensaio, trabalhamos a ideia de justiça em dois sentidos: justiça retributiva-comutativa e justiça distributiva, nos mesmos termos da tradição aristotélica.

Em linhas gerais, abordamos a distinção entre esses dois tipos de justiça, os porquês e a relevância dessa distinção. Também abordamos, mediante um caso, como a confusão entre esses dois conceitos pode levar a uma falsa solução jurídica. Essas falsas soluções jurídicas têm muitas vezes suscitado debates no interior das teorias de direitos fundamentais, causando-lhes enorme embaraço.

O Judiciário tem se transformado numa arena de conflitos distributivos. Se provocado adequadamente, pode ser um poderoso instrumento de políticas públicas. Para isso, no entanto, é necessário saber manusear argumentos de justiça distributiva e justiça retributiva-comutativa, e ter claras as noções de bem comum e bem particular. O problema que atravessamos hoje é a determinação desses critérios de justiça distributiva. 
Os tribunais aplicam normas, mas estas possuem finalidades definidas por diferentes modelos de justiça. A primeira necessidade das decisões judiciais, portanto, é a correta identificação do modelo de justiça a ser aplicado. Com isso, a prática do direito se torna mais clara e justificável a qualquer pessoa. Mais que isso, havendo clareza na definição da tópica, é possível evitar decisões injustas, seja as que negam reiteradamente a existência de uma justiça distributiva, seja reforçando posições sociais adquiridas sob regimes iníquos política e economicamente (LIMA LOPES, I994b).

Muitos julgados que constroem políticas públicas conforme o modelo da decisão aqui analisada são festejados como garantidores de direitos fundamentais. No entanto, estas decisões ignoram problemas de justiça distributiva (há vagas em creches para as pessoas que não possuem acesso à justiça? Por que aquelas que desrespeitam uma ordem de chegada na distribuição e apelam ao Judiciário devem ser beneficiadas?), reafirmando a mesma lógica de justiça comutativa que mantém o status quo daqueles que concentram renda e propriedade no país. Decidir desse modo por não refletir sobre modelos de justiça é falta de consciência; decidir conscientemente, mas fingir que se aplica um modelo de justiça quando se aplica outro é mentira. Ambos estão errados.

Dessa forma, o Judiciário deve cumprir seu papel histórico num Estado democrático de direito, dando-se conta do modelo de Estado, de sociedade e de conflitos em que está inserido, adequando-se a eles, de modo a superar o paradigma novecentista em que tem estado calcado. Afinal, sua missão não se reduz à proteção da propriedade privada, mas se estende a reformas sociais a serem realizadas por jogadas racionais dentro de um sistema.

\section{Referências bibliográficas}

ARISTÓTELES. Ética a Nicômaco. $4^{\underline{a}}$ ed. Brasília: Universidade de Brasília, $200 \mathrm{I}$. DWORKIN, Ronald. Levando os direitos a sério. São Paulo: Martins Fontes, 2010. ENGISCH, Karl. Introdução ao pensamento jurídico. Lisboa: Calouste Goulbenkian, 2008. FARIA, José Eduardo. Direitos humanos, direitos sociais e justiça. I ${ }^{a}$ ed. São Paulo: Malheiros, I994.

GUEST, Stephen. Ronald Dworkin. Rio de Janeiro: Elsevier, 2010. HART, H. L. A. O conceito de direito. Iํe ed. São Paulo: Martins Fontes, 2012. KELSEN, Hans. Teoria pura do direito. São Paulo: Martins Fontes, 2010.

LIMA LOPES, José Reinaldo. Juízo jurídico e a falsa solução dos princípios e das regras. Revista de Informação Legislativa, ano 40, no ${ }^{\circ}$ 160, 2003. 
Justiça e Poder Judiciário ou a virtude confronta a instituição. Revista da USP, nำ 2I, I994a.

- Direito subjetivo e direitos sociais: o dilema do Judiciário no Estado social de direito. In: FARIA, José Eduardo (org.). Direitos humanos, direitos sociais ejustiça. I $\mathrm{I}^{\mathrm{a}}$ ed. São Paulo: Malheiros, I994b.

MacCORMICK, Neil. A moralistic case for a-moralistic law. University Law Review. Valparaiso, vol. 20, $\mathrm{n}^{\circ} \mathrm{I}$, I985.

. Argumentação jurídica e teoria do direito. São Paulo: Martins Fontes, 2008.

NAGEL, Thomas. A última palavra. São Paulo: Unesp, 200 I.

. The point of view of nowhere. Oxford: Oxford University Press, I989.

RAWLS, John Political liberalism. Nova York: Columbia University Press, I993.

SEARLE, John. Mente, linguagem e sociedade: filosofia no mundo real. Rio de Janeiro: Rocco, 2000.

\section{Legislação}

BRASIL. Constituição (I988) Constituição da República Federativa do Brasil. Brasília, DF: Senado, I988. Disponível em: <http://www.planalto.gov.br/ ccivil_o3/constituicao/ConstituicaoCompilado.htm $>$.

BRASIL. Estatuto da Criança e do Adolescente. Lei no 8.069, de I3 de julho de I990. Dispõe sobre o Estatuto da Criança e do Adolescente e dá outras providências. Disponível em: <http://www.planalto.gov.br/ccivil_o3/leis/ 18069.htm>.

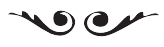

Maike Wile dos Santos e Yan Villela Vieira - Graduandos em Direito pela Universidade de São Paulo. maikewsantos@gmail.com; yanvvieira@gmail.com 